\title{
Merleau-Ponty y la ontología de la naturaleza: intercorporalidad, negatividad y dialéctica
}

\section{Merleau-Ponty and the ontology of the nature: intercorporaelity, negativity and dialectics}

Resumen: El objetivo del siguiente trabajo es abordar la forma en que la elaboración de una ontología de la naturaleza por parte de Merleau-Ponty se circunscribe al intento de elaborar un pensamiento del Ser que no haga de este un elemento del pensamiento abstracto, sino que dé cuenta de la experiencia concreta del ser en el mundo. En este sentido, son fundamentales los conceptos de intercorporalidad, de negatividad y de dialéctica.

Palabras claves: Fenomenología, Intersubjetividad, Husserl, Sartre, Carne.

\begin{abstract}
The aim of the following work is to approach the form in which the production of an ontology of the nature on the part of Merleau-Ponty limits itself to the attempt of elaborating a thought of the Being who does not do of this one an element of the abstract thought, but it realizes of the concrete experience of the being in the world. In this respect, the concepts are fundamental of intercorporeality, of negativity and of dialectics.
\end{abstract}

Keywords: Phenomenology, Intersubjectivity, Husserl, Sartre, Flesh. 


\section{I.- Introducción}

En un breve escrito, que lleva el nombre de "Títulos y trabajos"1, Merleau-Ponty explícita que el objetivo de su obra ha sido pensar "una tercera dimensión" o "medio común" en el que deben converger los puntos de vista extremos provenientes tanto de la ciencia positiva como de cierta actitud filosófica. Conciencia y cuerpo, naturaleza y cultura, idealismo y realismo, son algunas de las oposiciones que se han presentado a lo largo del pensamiento moderno, oposiciones que, en más de una ocasión, han sido pensadas ya sea a partir de una actitud objetivista, que piensa al hombre como el resultado de los condicionamientos psíquicos, sociales o históricos o de una filosofía intelectualista, que desde la conciencia "constituye todo ser y todo valor y nada puede entrar desde afuera en el sujeto pensante". Más precisamente, esta tercera dimensión se ubica entre el idealismo de la filosofía y el realismo de las ciencias, lo que significa ubicarse en un punto intermedio entre una perspectiva interior y una perspectiva exterior respecto a la consideración del hombre ${ }^{2}$. Dicho objetivo atraviesa tanto sus primeras obras como las últimas. Desde La estructura del comportamiento y la Fenomenología de la percepción a Lo visible y lo invisible, Merleau-Ponty ha intentado situar su pensamiento por fuera de los dualismos, al mismo tiempo que ha intentado develar la verdad parcial que encierra cada una de estas actitudes.

En el intento merleau-pontyano por pensar el suelo común de los elementos que suelen presentarse como antagónicos tiene una importancia medular el concepto de

\footnotetext{
${ }^{1}$ Merleau-Ponty, M., Parcours deux 1951-1961, Lonrai, Verdier, 2000.

${ }^{2}$ En este texto Merleau-Ponty afirma: "Esta revisión supone un doble enfoque de nuestra condición. Es necesario, por un lado, seguir el desarrollo espontáneo del saber positivo, preguntándonos si el saber positivo reduce verdaderamente al hombre a la condición de objeto, y, por otra parte, volver a examinar la actitud reflexiva y filosófica, para investigar si nos autoriza efectivamente a definirnos como sujetos incondicionados e intemporales. Quizás estas investigaciones convergentes finalicen por poner en evidencia un medio común de la filosofía y del saber positivo, y nos revelen, más acá del sujeto y del objeto puro, como una tercera dimensión donde nuestra actividad y nuestra pasividad, nuestra autonomía y nuestra dependencia, dejen de ser contradictorias" (Merleau-Ponty, Maurice, Parcours deux 1951-1961, p. 13).
} 
naturaleza. Sin embargo, la forma en que esta es pensada no se corresponde a la forma en que ha sido pensada habitualmente por la filosofía moderna, esto es, como un mero objeto de conocimiento. Por el contrario, ya en la Fenomenología de la percepción la naturaleza se presenta como un "ser permanente", como aquello que mantiene la identidad en el cambio ${ }^{3}$. La naturaleza merleau-pontyana, por tanto, no es ni la res extensa cartesiana, ni lo constituido por el sujeto trascendental kantiano, ni el en-sí sartreano ${ }^{4}$.

En sus últimos escritos, y particularmente en Lo visible y lo invisible, Merleau-Ponty profundiza la noción de naturaleza que habitaba ya en sus primeros textos, para constituir una ontología que trasvase los límites del pensamiento moderno. Una ontología de la naturaleza supone una ontología del "ser salvaje", lo que significa una comprensión del ser que no es la comprensión ontoteológica de la metafísica tradicional, ni tampoco una comprensión que conciba al ser como pura positividad, al estilo de la ontología sartreana. Esta apertura a una nueva forma de ontología es presentada ya explícitamente en el artículo "El filósofo y su sombra" y, luego, continuada y profundizada en sus trabajos posteriores.

A partir de ello, el objetivo del siguiente trabajo es abordar la forma en que MerleauPonty comienza a elaborar una ontología de la naturaleza que no se limita a comprenderla ni a partir del "puro objeto" ni del "puro sujeto" sino que se presenta como aquella tercera dimensión que antecede a la oposición sujeto-objeto. Con esta finalidad, trabajaremos tres ejes: el primero, la forma en que en el artículo "El filosofó

\footnotetext{
${ }^{3}$ Cf., Merleau-Ponty, M., Phénoménologie de la perception, Paris, Gallimard, 1945, p. 381.

${ }^{4}$ En los Cursos sobre la Naturaleza, Merleau-Ponty lleva a cabo una crítica a la concepción moderna de la naturaleza como pura objetividad. Descartes y Kant serían dos de los mayores representantes de dicha concepción. Sin embargo, vale la aclaración, el filósofo francés señala sentidos laterales en los pensamientos de Descartes y Kant que, sin llegar a desarrollarse, hubieran podido constituir un sentido alternativo (Merleau-Ponty, M., La Nature. Notes. Cours Collége du France, Paris, Gallimard, 1995). Con respecto a Sartre, en el segundo punto de este trabajo nos detendremos en las críticas que MerleauPonty realiza a la división ontológica entre el en-sí y el para-sí.
} 
y su sombra" Merleau-Ponty, mediante una relectura de las Ideas II de Husserl, propone una rehabilitación ontológica de lo sensible; el segundo, la manera en que se presentan las críticas a la ontología sartreana y la caracterización de ella como un pensamiento alejado de la experiencia concreta del hombre en el mundo; el tercero, la constitución de la "carne" como elemento en el sentido griego del término, a partir del cual se abre la posibilidad de una ontología que no reduzca ni el ser ni la naturaleza a una simple categoría del pensamiento abstracto.

\section{II.- La rehabilitación ontológica de lo sensible}

En el artículo "El filósofo y su sombra", Merleau-Ponty retoma el tema de la reducción, para intentar pensar lo "impensado" por el filósofo alemán. Esta idea de pensar "lo impensado" por un autor, se enmarca dentro de la tesis merleau-pontyana acerca de intentar establecer una forma de comprender la historia de la filosofía que no sea ni una historia "objetiva" de la filosofía, ni una meditación, disfrazada de diálogo, en donde el filósofo estudiado se transforma en un simple medio para la afirmación del propio pensamiento. Para Merleau-Ponty “(...) tiene que haber un término medio en que el filósofo del que se habla y el que habla estén presentes, juntos, aunque sea imposible discernir en todo momento que pertenece a cada uno" 5 .

En varias de sus obras se encuentra presente esta forma de leer a los filósofos anteriores: Descartes, Kant, Schelling, Hegel, Marx, el propio Husserl son algunos ejemplos. Ahora bien, el propósito de este apartado no es exponer la forma en que Merleau-Ponty problematiza las tesis husserlianas, sino abordar la manera en que, a partir de su lectura, continúa elaborando su propia concepción de la naturaleza,

\footnotetext{
${ }^{5}$ Merleau-Ponty, M., Signes, Paris, Gallimard, 1960, p. 201.
} 
concepción que implicará una ontología de la naturaleza que, en Lo visible y lo invisible, adquirirá su más alta expresión.

En el artículo mencionado, Merleau-Ponty señala que la operación más propia de la fenomenología es desvelar las capas preteóricas que subyacen al pensamiento reflexivo. Para lo cual sostiene que el carácter relativo de la naturaleza y el carácter irrelativo del espíritu se difuminan cuando se emprende el camino arqueológico que va de lo reflexivo a lo prerreflexivo. La idea de una naturaleza en-sí, relativa a un sujeto, sólo es posible a partir de la actitud teórico-reflexiva. "Antes de la reflexión, en la conversación, en la vida normal, nosotros mantenemos una actitud personalista de la que el naturalismo no puede dar cuenta, y las cosas son para nosotros, no naturaleza en sí, sino lo que nos rodea"6.

Es interesante destacar que si, en Sartre, la conciencia aparecía como el absoluto no substancial, lo que implicaba su carácter de "irrelativo", en Merleau-Ponty, a partir del camino regresivo-arqueológico que emprende, el carácter absoluto de la conciencia se disuelve en una indiferenciación que trasvasa las posibilidades de establecer los límites entre el hombre y la naturaleza. Precisamente, la naturaleza no es aquello que está "frente" al hombre, sino que es aquello que lo rodea y aquello desde donde surge. Esto implica que hay una resignificación de la intencionalidad fenomenológica que excede la correlación conciencia/mundo, para-sí/en-sí.

La intencionalidad que une los momentos de mi exploración, los aspectos de la cosa, y las dos series una con otra, no es la actividad de unión del sujeto espiritual, no son las puras conexiones del objeto, es la transición que efectúo como sujeto carnal de una fase del movimiento a la otra,

\footnotetext{
${ }^{6}$ Ibíd., p. 206.
} 
siempre posible para mí por principio porque soy este animal de percepciones y de movimientos que se llama un cuerpo ${ }^{7}$.

La comprensión merleau-pontyana de la intencionalidad como la transición de una fase del movimiento a otra significa un despliegue conceptual que va de la conciencia a la compresión del sujeto como sujeto encarnado. La aparición de la definición del cuerpo como animal de percepciones y de movimientos implica la emergencia del problema de la "animalidad" como instancia originaria de la existencia humana. Para el fenomenólogo francés, no hay un quiebre entre ambas dimensiones, por lo que se abre la posibilidad de una rehabilitación ontológica de lo sensible. Esta rehabilitación ontológica de lo sensible posibilita la apertura a un "genero del ser"8 que no se corresponde ni con el en-sí sartreano, ni con el ser de la metafísica tradicional.

A partir de la rehabilitación de una ontología de lo sensible, se abre una nueva instancia en la que el cogito se extiende sobre un mundo que siempre lo excede y que, a la vez, lo soporta. "Al conocer que mi cuerpo es cosa que siente, que es excitable - no sólo mi conciencia sino también él -, me he preparado para comprender que hay otros animalia y posiblemente otros hombres"9. Merleau-Ponty señala que no se trata de un proceso de analogía, ni de proyección, ni de introyección. La posibilidad de una ontología de lo sensible, por el contrario, pone de manifiesto el cohabitar efectivo de mi cuerpo con otros cuerpos, trasvasando y superando las antinomias del solipsismo fundadas en el pensamiento reflexivo.

$\mathrm{Si}$, al estrechar la mano de otro hombre, tengo la evidencia de que está aquí, es que ella sustituye a mi mano izquierda, que mi cuerpo se anexiona el cuerpo de otro en esta especie de

\footnotetext{
${ }^{7}$ Ibíd., p. 212.

${ }^{8}$ Ibíd.

${ }^{9}$ Ibíd., p. 213.
} 
reflexión de la cual es, paradójicamente, la sede. Mis dos manos son co-presentes o coexisten porque son las manos de un cuerpo: lo ajeno aparece por extensión de esta co-presencia, él y yo somos como los órganos de una única intercorporalidad ${ }^{10}$.

Este último concepto, el de intercorporalidad, aparece como un estamento más originario que el de "intersubjetividad". Es posible encontrar, en este punto, la continuidad, y a la vez, profundización de ciertas tesis que ya estaban presentes en la Fenomenología de la percepción. En la obra de 1945, Merleau-Ponty hablaba del cuerpo del otro como la extensión y reverso de mi propio cuerpo.

Experimento mi cuerpo como facultad de determinadas conductas y de un determinado mundo, me soy dado a mí mismo con un determinado dominio sobre el mundo; ahora bien, es justamente mi cuerpo el que percibe el cuerpo del Otro y encuentra en él algo así como una prolongación milagrosa de sus propias intenciones, una manera similar de tratar el mundo de ahí para adelante, puesto que las partes de mi cuerpo forman en conjunto un sistema, el cuerpo del otro y el mío forman un solo todo, el reverso y el anverso de un fenómeno único, y la existencia anónima cuya huella es mi cuerpo en todo momento habita de aquí en adelante dos cuerpos a la vez ${ }^{11}$.

En "El filósofo y su sombra" puede verse una radicalización de la tesis presentada en la Fenomenología de la percepción. Mi cuerpo y el cuerpo del otro se presentan como partes de una misma intercorporalidad. Esta intercorporalidad, a su vez, antecede a la constitución de la subjetividad. En este aspecto, Merleau-Ponty reafirma lo dicho en las obras anteriores: la coexistencia es previa a todo conflicto y, por tanto, es previa, también, a la distinción entre el "yo" y el "otro".

\footnotetext{
10 Ibíd.

${ }^{11}$ Merleau-Ponty, M. , Phénoménologie de la perception, p. 406.
} 
Desde el punto de vista solipsista, pues, lo ajeno no es imposible, porque la cosa sensible es abierta. Se convierte en algo actual cuando otro comportamiento y otra mirada toman posesión de mis cosas, y esto se lleva a cabo, esta articulación de otra corporeidad sobre mi mundo se efectúa sin introyección, porque mis posibles sensibles, por su aspecto, su configuración, su disposición carnal, realizaban ya el milagro de cosas que son cosas por el hecho de que se ofrecen a un cuerpo, hacían de mi corporeidad una prueba de $\operatorname{ser}^{12}$.

Merleau-Ponty habla de un "milagro" que posibilita la relación entre el hombre y las cosas. Ahora bien, ese "ser" que tiene como prueba dicho "milagro" es el fundamento de una intercorporalidad originaria que subyace a los procesos de individuación. El movimiento regresivo del pensamiento merleau-pontyano lleva hacia las capas más originarias de la existencia, en donde la indistinción es constituyente de toda distinción: de la conciencia al cuerpo, del cuerpo a la intercorporalidad, de la intercorporalidad a la animalidad, de la animalidad a una ontología de lo sensible en donde se presenta una concepción del ser donde este no es considerado, como se ha dicho, ni en el modo del en-sí sartreano, ni en el de la metafísica tradicional. En este punto, se abre la cuestión acerca de qué entiende Merleau-Ponty por ese "ser" que no puede ser reducido ni al mero ser objetivo, ni al pensamiento metafísico tradicional.

El hecho es que lo sensible, que se me anuncia en mi más estricta vida privada, interpela en ella a cualquier otra corporeidad. Es el ser que me alcanza en lo más secreto, pero que yo alcanzo también en el estado bruto o salvaje, en un absoluto de presencia que posee el secreto del mundo, de los y de lo verdadero ${ }^{13}$.

\footnotetext{
${ }^{12}$ Merleau-Ponty, M., Signes, p. 217.

${ }^{13}$ Ibíd., p. 216
} 
Merleau-Ponty retoma dos términos de Schelling, para hacer referencia a ese "ser" originario que emergería a partir de una ontología de lo sensible, "bruto" y "salvaje"14. Frente al pensamiento teórico-reflexivo que encuentra su anclaje en la cartesiana idea de lo "claro" y "distinto", la concepción de un ser bruto o salvaje se presenta como posibilidad de una ontología que se encuentre "más acá"15 de la reflexión. El ser que se nos revela en este estado no puede ser confundido ni por Dios ni por la Idea. Ambos son conceptos que el pensamiento especulativo circunscribe, delimita, en suma, que reduce a categorías intelectuales diferenciadas, con mayor o menor complejidad, con mayor o menor sutileza. Por el contrario, el ser absoluto que posee el secreto del mundo, que no es ni Dios ni la Idea, tiene algo de indeterminado, de ambiguo, de inaprensible. Es, precisamente, un ser bruto y salvaje. Merleau-Ponty sostiene que ese ser es la propia naturaleza.

Existen unos objetos que no están presentes originariamente sólo para un objeto, sino que si lo están para un sujeto, pueden darse en presencia originaria a todos los otros sujetos (desde el momento en que estos se hayan constituido). La totalidad de los objetos que pueden estar presentes originariamente, y que para todos los sujetos comunicantes constituyen un dominio común, es la Naturaleza en el sentido primario y originario ${ }^{16}$.

\footnotetext{
${ }^{14}$ En los Cursos sobre la Naturaleza. Merleau-Ponty retoma varios de los planteos de Schelling, y ve en ellos una radicalidad en la forma de comprender la naturaleza que no se encuentra en otros autores modernos. Según Merleau-Ponty Schelling no reduce la naturaleza a un mero objeto, sino que, por el contrario ve en ella un polo de latencias, fisuras, donde la actividad y la pasividad se entrecruzan recíprocamente. "La naturaleza es a la vez pasiva y activa, producto y productividad (...)" (MerleauPonty, M., La Nature. Notes. Cours Collége du France, p. 60)

${ }^{15}$ El concepto de "más acá" es empleado por Merleau-Ponty en la nota "Filosofía y no-filosofía después de Hegel" para referirse a una forma de comprender la filosofía y el pensamiento de lo absoluto que no recaiga en una metafísica. "(...) filosofía negativa, en el sentido de "“teología negativa', que se abre acceso a lo absoluto, no como "más allá", un segundo un orden positivo, sino como otro orden que exige el más acá, el doble, que solo es accesible a través de él" (Merleau-Ponty, M., Notes des cours au Collège de France 1958-1959 et 1960-1961, Gallimard, Paris, 1996, p.275). En relación con la interpretación de la temática Filosofía y no filosofía consultar el trabajo de Francoise Dastur, «Philosophie et nonphilosophie » en Chair sur Merleau-Ponty. Essais sur Merleau-Ponty, La Versanne, Encre Marine, 2001, pp.139-145.)

${ }^{16}$ Merleau-Ponty, M. , Signes, p. 216.
} 
La naturaleza se presenta como ese ser originario, como ese dominio común desde donde emergen los objetos y los demás sujetos. Sin embargo, Merleau-Ponty se encarga de aclarar que no se trata de la concepción kantiana de la naturaleza como conjunto de todos los entes. En este aspecto, la naturaleza también está marcada por ausencias y, también por negatividades. Ya no se trata, pues, de pensar la naturaleza como presencia o pura positividad. Esto implica también una reconfiguración del sentido de lo sensible. Precisamente, en este punto, Merleau-Ponty opone a Kant y a Husserl.

Correlativamente, cualesquiera que sean mis pretensiones para aprehender el ser mismo en lo que percibo, estoy a los ojos de los demás encerrado en mis representaciones, permanezco ante su mundo sensible y sin entrar en él, y lo trasciendo. Pero esto ocurre porque usamos una noción mutilada de lo sensible y de la Naturaleza. Kant decía que esta era el conjunto de todos los entes. Husserl encuentra lo sensible como forma universal del ser bruto ${ }^{17}$.

El paradigma moderno de la naturaleza queda convertido en una construcción intelectual de segundo grado. En su dimensión originaria, la naturaleza no es un mero objeto, sino que precede a la distinción "sujeto-objeto". En este aspecto, Merleau-Ponty articula algunos de los pensamientos esbozados por Husserl con las concepciones ontológicas de Schelling, lo que lo lleva a diluir la división tajante entre el mundo de la naturaleza y el mundo del espíritu.

Lo que resiste en nosotros a la fenomenología - el ser natural, el principio bárbaro del que hablaba Schelling - no puede permanecer fuera de la fenomenología y debe tener su sitio en ella. El filósofo tiene su sombra que se presenta, que no es simple ausencia de hecho de la futura

\footnotetext{
${ }^{17}$ Ibíd., p. 217.
} 
luz. "Es una dificultad ya muy excepcional", dice Husserl, no sólo "captar" sino "comprender" desde el interior la relación del "mundo de la Naturaleza" y del "mundo del espíritu"18.

Existe, por lo tanto, el desafío de comprender la relación entre el mundo del espíritu y el mundo de la naturaleza por fuera de la reducción a un simple antagonismo. MerleauPonty señala que estos planteos ya pueden hallarse en Husserl, al menos de manera lateral.

Este mundo barroco no es una concesión del espíritu a la naturaleza: aunque siempre se trata de un sentido figurado, de todas formas es un sentido. Esta renovación del mundo es también una renovación del espíritu, es descubrir de nuevo el espíritu bruto que no se encuentra aprisionado por ninguna de las culturas al cual se pide que cree de nuevo la cultura. Lo irrelativo ya no es desde ahora la naturaleza en sí, ni el sistema de aprehensiones de la conciencia absoluta, ni tampoco el hombre, sino esta "teleología" de la que habla Husserl - que se escribe y se piensa entre comillas-, unión y armazón del Ser que se realiza a través del hombre ${ }^{19}$.

\section{III.- Las críticas al "negativismo” sartreano}

Las críticas de Merleau-Ponty al pensamiento de Sartre recorren varias de sus obras principales. En la Fenomenología de la percepción estas se encuentran presentes, sobre

\footnotetext{
${ }^{18}$ Ibíd., p. 225. Es el ser natural lo que resiste a la reflexión fenomenológica e impide la posibilidad de una reducción completa. En una intervención que Merleau-Ponty tuvo en el "Coloquio de Royaumont", estima que la reducción fue siempre presentada por Husserl como "una especie de paradoja y una especie de enigma". Los textos de Husserl dejan entrever que la dificultad planteada por la reducción no es una dificultad de hecho sino de derecho. Tal dificultad, según Merleau-Ponty, se manifiesta en la siguiente pregunta: “¿De dónde procede esta resistencia de lo prerreflexivo a la reflexión?”. A continuación agrega que esta resistencia no debe ser vista como una "adversidad sin nombre", ya que no se trata de una fuerza irracional que se contrapone a la reflexión, sino más bien, lo pre-reflexivo es el indicio de una experiencia que no puede ser absorbida por la conciencia y que forma parte de ella. La respuesta a esta resistencia se encuentra en la ontología. (Husserl, E., Tercer coloquio filosófico de Royaument, Buenos Aires, Paidos, p. 143).

${ }^{19}$ Merleau-Ponty, M., Signes, p. 228.
} 
todo, en los capítulos acerca de "La libertad" y "El otro y el mundo humano". En este último hay una crítica profunda a la comprensión sartreana del conflicto como relación originaria con el otro $^{20}$. A diferencia de Sartre, Merleau-Ponty reconoce un horizonte a partir del cual se da la relación con el otro que subyacería a la tesis sartreana acerca de la originariedad del conflicto.

Con el cogito empieza la lucha de las conciencias, en que cada una, como dice Hegel, persigue la muerte de la otra. Para que la lucha pueda empezar, para que toda conciencia pueda sospechar presencias ajenas que niega, es menester que tengan un terreno común y que rememoren su coexistencia pacífica en el mundo del niño ${ }^{21}$.

Cuando Merleau-Ponty habla de la aparición del cogito como momento de inicio de la lucha entre las conciencias, por un lado, señala la existencia de un proceso previo a dicha aparición y, por otro, hace una equiparación entre el ser para-sí sartreano con el cogito cartesiano. Con respecto a esto último, si bien el ser para-sí guarda notorias diferencias con el cogito cartesiano, es verdad que ambos se presentan como instancias originarias dentro de esquema de pensamiento de los dos filósofos. Precisamente, la ontología expuesta en El ser y la nada parte de la distinción entre dos regiones del ser: el ser en-sí y el ser para-sí. El ser para-sí es la conciencia. La definición ontológica que Sartre da del para-sí es que es el que no es y no es el que es ${ }^{22}$. Por su parte, el ser en-sí se define como el que es lo que es ${ }^{23}$. El ser en-sí, por lo tanto, se corresponde con la dimensión objetual del ser. Se trata de aquello que es revelado por la conciencia. En su

\footnotetext{
${ }^{20}$ El carácter originariamente agonístico de la relación con el otro es expuesto en El ser y la nada, principalmente en el capítulo "Las relaciones concretas con el Otro". Allí se ve con claridad la forma en que Sartre enlaza su ontología con la forma de comprender las relaciones interpersonales a partir de una dinámica subjetivación/objetivación. Este tema será retomado por Sartre también en varias de sus obras literarias (el ejemplo más reconocido es, sin lugar a dudas, A puertas cerradas).

${ }^{21}$ Merleau-Ponty, M. , Phénoménologie de la perception, p. 409.

${ }^{22}$ Sartre, J. P., L'être et le néant. Essai d'ontologie phénoménologique, Paris, Gallimard, 1943. p.33.

${ }^{23}$ Ibíd.
} 
ser más propio, el en-sí se presenta como pura positividad, como algo absolutamente macizo, opaco, si grietas ni fisuras.

Merleau-Ponty critica constantemente el carácter antitético del pensamiento de Sartre. En el artículo "La querella del existencialismo", si bien es un texto que el fenomenólogo francés escribe en defensa de Sartre tras las críticas a católicos y marxistas, aparece explícitamente la siguiente sentencia: “(...) el libro (El ser y la nada) es demasiado antitético: “(...) la antítesis de mi vista sobre mí mismo y del otro sobre mí, la antítesis del para-sí y del en-sí son a menudo presentados como alternativos, en lugar de ser descriptos como el lazo vivo del uno con el otro" ${ }^{24}$.

Estas críticas se extienden a Lo visible y lo invisible, donde Merleau-Ponty habla del pensamiento de Sartre como de un "negativismo absoluto". Precisamente, en su artículo "La crítica de la ontología sartreana en Lo visible y lo invisible"25, Philippe Cabestan señala que si bien “(...) no podemos sobrestimar la importancia de la obra de Sartre en la reflexión de Merleau-Ponty, ella está sin duda alguna presente en el punto que Lo visible y lo invisible - así como en Las aventuras de la dialéctica - consagra a Sartre״26. Cabestan se refiere explícitamente al capítulo "Interrogación y dialéctica", y más precisamente, al apartado sobre "La fe perceptiva y la negación". El intérprete realiza una sugestiva analogía entre el título de Lo visible y lo invisible y El ser y la nada. Según Cabestan, el reemplazo de los términos antagónicos, es decir de "ser" y "nada" a "visible" e "invisible", indica la intención de Merleau-Ponty de criticar al pensamiento sartreano $\mathrm{y}$, al mismo tiempo, buscar una forma alternativa de pensamiento que no recaiga en una lógica de oposiciones irreconciliables.

\footnotetext{
${ }^{24}$ Merleau-Ponty, M., Sens et non-sens, Paris, Nagel, 1963, p. 125.

${ }^{25}$ Cabestan, P. , "La critique de l'ontologie sartrene dans Le visible et l'invisible", Chiasmi Internacional N. 2. Merleau-Ponty de la nature à l'ontologie, VRIN, Paris, 2000. pp. 389-413.

${ }^{26}$ Ibíd., p. 389.
} 
En Lo visible y lo invisible, Merleau-Ponty dedica varias páginas a criticar la oposición sartreana entre el ser y la nada, como regiones ontológicas diferenciadas. Y, sobre todo, critica la forma en que Sartre concibe la relación entre ellas a partir de la negación. Como se ha señalado, Merleau-Ponty denomina al pensamiento de Sartre como "negativismo". Sin embargo, al mismo tiempo, sostiene que este "negativismo" ontológico termina siendo un positivismo.

Desde el punto de vista de una filosofía de la negatividad absoluta - que lo es también y al mismo tiempo de la positividad absoluta - se volatilizan todos los problemas de la filosofía clásica, pues, eran problemas de "mezcla" o de "unión", y mezcla y unión son imposibles entre lo que es y lo que no es, pero, por la misma razón que hace imposible pensar la mezcla, no puede pensarse lo uno sin pensar lo otro. Así desaparece la antinomia del idealismo y del realismo: a la vez es verdad que el "conocimiento" como nihilización sólo se sostiene por las cosas mismas en que se funda, que en modo alguno puede afectar al Ser $(\ldots)^{27}$.

En esta cita hay varios elementos para destacar. Cabe aclarar que se refiere explícitamente a la ontología expuesta en El ser y la nada ya que, en esas páginas, se encuentran citadas varias frases de la obra de Sartre. Por un lado, Merleau-Ponty equipara la filosofía de la negatividad absoluta a la filosofía de la positividad absoluta. Por otro, la supuesta "superación" de las antinomias entre idealismo y realismo que el pensamiento de lo negativo llevaría a cabo. En tercer lugar, la negativa sartreana a la idea de "mezcla", que podría extenderse a la merleau-pontyana noción de "ambigüedad",28.

\footnotetext{
${ }^{27}$ Merleau-Ponty, M. , Le visible et l'invisible, Paris, Gallimard, 1964, pp. 81-82.

${ }^{28}$ Merleau-Ponty distingue entre ambivalencia y ambigüedad. La "ambigüedad" no hace referencia a un pensamiento vacilante que afirma alternativamente los términos en cuestión, sino a"[...] un pensamiento que distingue las diferentes relaciones de las cosas, el movimiento interior que las hace participar de los contrarios" (Merleau-Ponty, M., Parcous deux, p. 340). Por su parte, la "ambivalencia" se desentiende de
} 
Por una parte, Merleau-Ponty evalúa que una filosofía de la negatividad absoluta es también una filosofía de la positividad absoluta. Lo central de este tipo de filosofías es que desde el momento en que separa "lo que es" y "lo que no es" impide pensar en la posibilidad de una "mezcla", esto es, pensar uno de los términos sin el otro. Por otra parte, no permite pensar la antinomia del idealismo y del realismo porque la disuelve.

Con respecto a lo primero, Merleau-Ponty señala que la radicalización de la nada lleva a una radicalización del ser. Cuando Sartre, en El ser y la nada, caracteriza al para-sí como nihilización que es su propia nada, hace, al mismo tiempo, una filosofía de una nada absoluta como de un ser absoluto. Merleau-Ponty señala que en Sartre “(...) la conciencia es inmanencia porque es nihilización, vacío, transparencia; y es abertura a cosas trascendentes porque ese vacío no sería nada por sí solo, porque la conciencia existente no tiene ningún poder motor, ya que es de un orden distinto"29.

Merleau-Ponty observa, al igual que lo había hecho en Las aventuras la dialéctica con respecto a la concepción de la historia, que las formas de pensamiento antagónicas culminan siendo más que similares ${ }^{30}$. En este caso, la filosofía de la nada planteada por

\footnotetext{
la aspiración a una clara intelección y, por lo tanto, queda descartada del pensamiento filosófico. En Elogio de la filosofía, Merleau-Ponty afirma: "El filósofo se reconoce en que tiene de modo inseparable el gusto por la evidencia y el sentido de la ambigüedad" (Cf. Merleau-Ponty, M., Éloge de la philosophie et autres essais, Paris, Gallimard, 1953, pp. 10-11). La ambigüedad no significa un fracaso del conocimiento o su imposibilidad; por el contrario, implica pensar que la situación total incluye tanto la conciencia lúcida como el riesgo del error.

${ }^{29}$ Merleau-Ponty, M. , Le visible et l'invisible, p. 82.

${ }^{30}$ En Las aventuras de la dialéctica, Merleau-Ponty habla del pensamiento de Sartre como un subjetivismo extremo. Sin embargo, este subjetivismo tendría como punto de contacto con el objetivismo del marxismo dogmático (léase doctrina oficial del PC y de la URSS), el hecho de ser igualmente terroristas frente al campo socio-cultural. "La filosofía del objeto puro y la del sujeto puro son igualmente terroristas" (Merleau-Ponty, M., Les aventures de la dialectique, Gallimard, Paris, 1955, p. 145). Esto se debería a que "(...) Sin duda este extremo subjetivismo y este extremo objetivismo tienen algo en común, pues si lo social es una segunda naturaleza, sólo puede ser modificada, como la otra por un técnico, que será una especie de ingeniero político. Y si lo social es solamente el residuo inerte y confuso de nuestras acciones pasadas, no se puede intervenir e imponer orden más que por una creación pura Merleau-Ponty, M., Les aventures de la dialectique, p. 144).
} 
Sartre $^{31}$ lleva a una consagración del ser como absoluta positividad, por lo que el radicalismo negativista lleva a un positivismo igual de radical.

Un pensamiento negativista es idénticamente un pensamiento positivista, y en este giro total sigue siendo el mismo en el sentido de que tanto si considera el vacío de la nada, como si considera la plenitud absoluta del ser, desconoce el grosos, la pluralidad de planos, los transmundos. Cuando, a partir de la nada llega a implantar el ser como plenitud y positividad absolutas - más cuando afirma que sólo hay ser y que el ser reclama e incluye en cierto sentido la nada-, no introduce elementos que hubiera excluido metódicamente antes, no se aproxima a lo concreto, no sigue las articulaciones del todo; compensa una abstracción con una contraabstracción $^{32}$.

En estas últimas palabras se devela el sentido que tiene, para Merleau-Ponty, el negativismo sartreano: el de ser una abstracción. El negativismo absoluto sería una expresión más del pensamiento reflexivo-especulativo, que es posterior a la experiencia originaria del ser en el mundo. Como se ha mencionado, Merleau-Ponty critica las posiciones extremas y, según él, el negativismo sería una de ellas.

En realidad la definición del ser como lo que es en todos los aspectos y sin restricción alguna, y la de la nada como que no es desde ningún punto de vista, esa apropiación por el pensamiento

\footnotetext{
${ }^{31}$ En este aspecto, hay que aclarar que la lectura que hace Merleau-Ponty de la lectura sartreana del parasí es una lectura personal. Merleau-Ponty sostiene que la "conciencia no podría tener ningún poder motor"; sin embargo, la nihilización se realiza en la acción y, para Sartre, esto no puede ser de otra manera ya que, si bien el para-sí es nada, se encuentra también revestido de ser. Como se ha visto, en $E l$ ser y la nada, no hay una imposibilidad de actuar, de ser poder motor, sino que la imposibilidad es la de no actuar. Por otro lado, aunque la diferencia entre el ser para-sí y el ser en-sí es de orden ontológico, la expresión de que se trata de dos "órdenes distintos" puede llevar a pensar en un dualismo ontológico, pero, en El ser y la nada, Sartre aclara que se trata de dos dimensiones que, no sólo se refieren necesariamente la una a la otra, sino que surgen de una misma raíz originaria.

${ }^{32}$ Merleau-Ponty, M. , Le visible et l'invisible., p. 96.
} 
de un ser inmediato y una nada inmediata, esa intuición y esa negintuición son el retrato abstracto de una experiencia, y hay que discutirlos en el campo de la experiencia ${ }^{33}$.

Ahora bien, en este punto es interesante destacar la lectura que hace Merleau-Ponty del polo antagónico del negativismo sartreano: el positivismo de Bergson. En el artículo "Naturaleza y negación: Merleau-Ponty lector de Bergson",34, Ted Toadvine indica que las alusiones que Merleau-Ponty realiza del autor de La energía espiritual, tanto en la Fenomenología de la percepción como en La estructura del comportamiento, se mantienen en una línea crítica. Esta visión crítica del pensamiento continúa en los Cursos sobre la Naturaleza. Para Merleau-Ponty hay en Bergson un positivismo radical que es, finalmente, un negativismo radical. En este sentido, habría una convergencia entre ciertas intuiciones de Bergson y ciertas intuiciones de Sartre.

A primera vista, Merleau-Ponty indica que si bien puede parecer paradojal comparar dos filosofías, donde una es esencialmente positivista, y la otra, esencialmente negativista, ninguna de las dos admite una mezcla del ser y de la nada. Con Sartre, la nada está ávida de ser, y lo que hay es un equívoco en la conciencia, un vano esfuerzo de la nada por hacerse ser. No hay lugar para una concepción de la naturaleza, ni para una concepción de la historia en esta filosofía. Con Bergson, ocurre lo mismo. El objeto es todo lo que es. Ningún principio lo mueve hacia adelante. Merleau-Ponty observa que hay en esto una transferencia de lo posible del ser al hombre. Sartre sostiene la idea que en la historia de una conciencia no hay faltas previas: el hombre crea a la vez su falta y su solución. De la misma manera, Bergson, en La evolución creadora, piensa que la filosofía crea, al mismo tiempo, los problemas y sus soluciones.

\footnotetext{
${ }^{33}$ Ibíd., p. 105.

34 Toadvine, T., "Nature and negation: Merleau-Ponty's Redding of Bergson”, Chiasmi International 2. Merleau-Ponty.De la Nature à l'ontologie, Paris, Vrin, 2000.
} 
Frente a ambas posiciones, Merleau-Ponty plantea la dialéctica como pensamiento alternativo. En el siguiente texto Merleau-Ponty sienta, con toda claridad, su posición respecto al modo de comprender la dialéctica.

La dialéctica no la idea de acción recíproca ni la idea de solidaridad de los contrarios y de su superación, ni tampoco de un desarrollo que se provoca a sí mismo, ni del transcrecimiento de una cualidad que instala en un nuevo orden un cambio que hasta ese entonces era cuantitativo: estas son consecuencias o aspectos de la dialéctica. Pero esas relaciones, tomadas por sí mismas o como propiedades del ser, son como prodigios, curiosidades o paradojas. Sólo aclaran cuando se las considera en nuestra experiencia, cuando se reúnen en un sujeto, en un ser y en otros sujetos; entre esos contrarios, en esa acción recíproca, en esa relación entre un interior y un exterior, en ese devenir que no sólo deviene sino que viene para sí, hay lugar, sin contradicción y sin magia, para que existan relaciones de doble sentido, para vuelcos, para verdades contrarias e inseparables, para superaciones, para una génesis perpetua, para una pluralidad de planos o de órdenes. Sólo hay dialéctica en ese tipo de ser en el que se realiza la convergencia de los sujetos y que no es solamente un espectáculo que se proporciona cada uno de ellos por su cuenta, sino su residencia común, el lugar de sus intercambios y de sus inserciones recíprocas ${ }^{35}$.

Esta comprensión de la dialéctica va a atravesar varios de los últimos escritos de Merleau-Ponty. En uno de sus resúmenes de cursos en el Collège de France, MerleauPonty enumera tres elementos que constituyen la dialéctica. Por un lado, es un pensamiento de las contradicciones pero que no busca anular la oposición sino que mantiene siempre la tensión entre las partes contrarias. Por otro, que es un pensamiento subjetivo, ya que no toma al ser en-sí, de manera objetiva, sino que establece un nuevo sentido de la subjetividad y de su relación con el mundo. La tercera característica propia de la dialéctica es que se trata de un pensamiento circular. "Puesto que no quiere

\footnotetext{
${ }^{35}$ Merleau-Ponty, M., Le visible et l'invisible, p. 297.
} 
sacrificar lo uno a lo otro, ni lo reflexivo a la reflexión, el pensamiento dialéctico se presenta ante sí mismo como desarrollo (...) de lo que existía antes de él, y del mismo modo sus conclusiones conservarán en sí mismas todo el progreso que condujo hacia ellas"36.

En este mismo texto, Merleau-Ponty reconoce ciertos aspectos de la concepción de la dialéctica sostenida por Platón en sus textos de vejez. En el Sofista se realiza una dialéctica que no lleva a ninguna superación sino que se mueve entre las ambivalencias de los términos, de la reciprocidad entre ellos. Esta idea de una dialéctica que no busca superaciones, que no es ni "descendente" ni "ascendente", que no busca conciliar ni anular a los opuestos, sino pensar el lazo que los une, la manera en que cada elemento nos remite a los otros, es fundamental para Merleau-Ponty. "El Parménides de Platón, y también el Teeteto y el Sofista, han sido estudiados como ejemplos de una dialéctica que no es ascendente ni descendente y que se mantiene, por así decir, en su lugar" constituido" 37 .

Por su parte, en Historia de una amistad, a partir de esta concepción "circular" de la dialéctica, Sartre cuestiona el carácter dialéctico del pensamiento de Merleau-Ponty. “Así, girando y meditando, Merleau permanece fiel a su pensamiento espontáneo -lenta rumia interrumpida por súbitos relámpagos- y es a este pensamiento al que erige discretamente en método bajo la forma de una dialéctica decapitada" ${ }^{38}$. La expresión "dialéctica decapitada" hace referencia a la ausencia de síntesis superadoras. Sartre señala el carácter circular del pensamiento merleau-pontyano, la idea de ver siempre entre los opuestos una naturaleza común, “(...) de seguir cada No hasta que se convierte en Sí y cada Sí hasta verlo transformado en No" ${ }^{\text {39 }}$. Si bien Sartre reconoce que Merleau-

\footnotetext{
${ }^{36}$ Merleau-Ponty, M., Résumés de cours. Collège de France 1952-1960, pp.78-82.

${ }^{37}$ Ibíd., p. 81.

${ }^{38}$ Sartre, J. P., Situations IV. Portraits, 282.

${ }^{39}$ Ibíd., p. 283.
} 
Ponty comprende el punto de partida del pensamiento dialéctico, habla de un juego de hurón, a través del cual todo es verdadero y “(...) donde las verdades contradictorias en él nunca se combaten (...),40. En este punto, Sartre menciona el reconocimiento que Merleau-Ponty realiza de algunos puntos de la filosofía de Platón. "Merleau conserva sus coqueterías: en este texto habla aún de la dialéctica. Pero no es Hegel a quien se refiere sino a Parménides, a Platón" ${ }^{41}$. Esto hace que Sartre cuestione dicho carácter dialéctico ya que, para él, la dialéctica es la dialéctica hegeliana, aún a pesar de las críticas que puedan hacérsele a Hegel.

En Las aventuras de la dialéctica Merleau-Ponty sostiene que la dialéctica, pues, sólo puede ser concebida “(...) como la expresión o la verdad de una experiencia donde el comercio de los sujetos entre sí y con el ser, estaba previamente constituido" ${ }^{\text {42. El }}$ pensamiento dialéctico es, por lo tanto, un pensamiento situado en ese intermundo que significa un pliegue a partir del cual se dan las relaciones de reciprocidad entre términos que, a primera vista, podrían ser considerados antagónicos.

Volviendo a Lo visible y lo invisible, la dialéctica es pensada como movimiento inherente al Ser.

Dicho en otros términos, lo que excluimos de la dialéctica es la idea de lo negativo puro; lo que buscamos es una definición dialéctica del ser, que no puede ser el ser para-sí, ni el ser en-sí - definiciones rápidas, frágiles, inconsistentes que, como dijo muy bien Hegel, nos llevan de una a la otra-, ni el en-sí-para-sí, que es el colmo de la ambivalencia (...), que ha de dar con el ser antes de que se produzca la escisión reflexiva, alrededor de ella, su horizonte, no fuera de nosotros, ni en nosotros, sino donde se cruzan ambos movimientos, donde hay algo ${ }^{43}$

\footnotetext{
${ }^{40}$ Ibíd.

${ }^{41}$ Ibíd., p. 284.

${ }^{42}$ Merleau-Ponty, M., Les aventures de la dialectique, p. 298.

${ }^{43}$ Merleau-Ponty, M., Le visible et l'invisible. P. 128.
} 
VI) La carne como elemento

En Lo visible y lo invisible, Merleau-Ponty comienza a articular un concepto a partir del cual se pueda pensar una ontología que no recaiga en lo que él llama "actitudes extremas", es decir que se encuentre por fuera de todo dualismo. Sin embargo, no se trata de un monismo metafísico, comprendiendo "metafísico" como algo que se encuentra "más allá" de lo sensible. Por el contrario, el concepto que desarrolla se da a partir del proyecto presentado en el artículo antes trabajado, "El filósofo y su sombra", de rehabilitar una ontología de lo sensible. Este concepto es el concepto de "carne".

La carne, pues, no se halla "más allá" de la existencia fáctica, no es un metà tá, sino que se encuentra "más acá". Por lo tanto, la carne no debe ser pensada como un principio trascendente a la physis, al contrario, la carne se encuentra emparentada con la physis misma, tal como esta era pensada por los presocráticos. Precisamente, el propio Merleau-Ponty afirma que la carne es un elemento. Y, el concepto de elemento que utiliza, es el concepto griego.

Para designarla haría falta el viejo término de "elemento", en el sentido que se empleaba para hablar del agua, del aire, de la tierra y del fuego, es decir de una cosa general, a mitad de camino entre el individuo espacio-temporal y la idea, especie de principio encarnado que introduce un estilo de ser dondequiera que haya una simple parcela suya ${ }^{44}$.

Con la comprensión de la carne como elemento, Merleau-Ponty se aleja de la binaria oposición materia/espíritu. La carne no es ni materia ni espíritu. "La carne no es materia en el sentido de corpúsculos de ser que se suman o se prolongan para formar los

\footnotetext{
${ }^{44}$ Ibíd., p. 184.
} 
seres”,45. Al mismo tiempo, Merleau-Ponty sostiene que: “(...) ni tampoco es representación para un espíritu"46. Si "espíritu” y "materia” eran polos antagónicos dentro del pensamiento ontológico moderno, la "carne" se ubica a igual distancia de una como del otro. Ni Kant ni Engels, son, por lo tanto, los puntos de referencia de MerleauPonty al plantear esta dimensión ontológica. Sí aparece, como se ha visto en el primer apartado, la influencia de Schelling, ya que la carne aparece relacionada con el “principio bárbaro" y con la naturaleza. En algún punto, también puede ser comprendida en relación con el absoluto hegeliano, según la interpretación realizada por MerleauPonty en "Filosofía y no-filosofía después de Hegel". Es decir, una forma de comprender lo absoluto que se encuentra, nuevamente, "más acá” de la relación sujetoobjeto $^{47}$.

La carne, en tanto elemento, se presenta, entonces, como aquello que envuelve todo lo existente. La relación entre el vidente y lo visto, entre la mirada y lo mirado, se articula y posibilita a partir de este elemento originario, que envuelve tanto a uno como a otro polo de la relación.

Lo que hay, pues, no son cosas idénticas a sí mismas, que ofrecen ulteriormente al vidente, y tampoco es un vidente, vacío al principio quien después se abre a ellas, sino algo a lo que sólo podemos acceder palpándolo con la mirada, cosas que no podemos aspirar a ver desnudas porque la mirada las envuelve, las viste con su carne ${ }^{48}$.

\footnotetext{
${ }^{45}$ Ibíd., p. 183.

${ }^{46}$ Ibíd., p. 184.

${ }^{47}$ En esta nota de curso, Merleau-Ponty habla del absoluto hegeliano como algo que se da al contacto de nuestra vida. "Se intenta captar la relación del Erkennen con lo Absoluto como dada en nuestra vida (pues se trata de un Absoluto que será también Erkennen), de refundar los conceptos de subjetividad y objetividad, absoluto y conocimiento al contacto con nuestra vida (...)" (Merleau-Ponty, M., Notes des cours au Collège de France 1958-1959 et 1960-1961, p. 282).

${ }^{48}$ Ibíd., p. 173.
} 
Merleau-Ponty habla de una "carne" de la mirada, lo que deja en claro que la carne no puede ser reducida a un principio materialista. De la misma manera, se ve una distancia enorme con la forma de comprender la mirada que posee Sartre ${ }^{49}$. La mirada, a partir de la ontología de la carne, no es poder de objetivación del para-sí frente a la desnudez de otro para-sí. La mirada sólo es posible, para Merleau-Ponty, a partir de este envolvimiento común de la carne tanto del que mira como del que es visto.

En el anteriormente citado artículo de Phillipe Cabestan, el intérprete sostiene que, en esta última etapa, hay, por parte de Merleau-Ponty, un alejamiento de la fenomenología, tanto husserliana como sartreana, y un acercamiento a la ontología del Heidegger post$K_{e h r}{ }^{50}$. Sí bien no es este el tema del presente trabajo, sí podría decirse, por un lado, que, como se ha visto hasta ahora, la distancia con la ontología sartreana está presente desde los primeros textos de Merleau-Ponty; y, por otro, que el proyecto de una "ontología de lo sensible" e incluso el concepto de carne aparecen ya planteados en "El filósofo y su sombra", donde, como también se ha visto, Merleau-Ponty lleva a cabo una relectura de Ideas II de Husserl. Sin embargo, es cierto que hay una profundización ontológica en donde la idea de la intencionalidad es desplazada por la conceptualización de una ontología originaria que preceda a la conciencia.

Ahora bien, con la comprensión de la carne como elemento, Merleau-Ponty descubre esa tercera dimensión que ha sido una búsqueda constante en sus trabajos. La carne se constituye como un pliegue que articula la totalidad de los existentes. En el caso del cuerpo propio y el cuerpo del otro, Merleau-Ponty profundiza las tesis que ya se encontraban presentes en la Fenomenología de la percepción y retoma el concepto de "intercorporalidad" presentado en "El filósofo y su sombra". "Si se ha dejado captar por

\footnotetext{
${ }^{49}$ En Ser y la nada, la mirada se corresponde a la dinámica subjetivación/objetivación como forma originaria del ser para-otro. No puedo mirar y ser mirado, sino que, o bien miro (lo que significa la objetivación del otro), o bien soy mirado (lo que significa mi objetivación).

${ }^{50}$ Merleau-Ponty, M., Signes, p. 218,
} 
uno de sus fragmentos, queda establecido el principio de captabilidad, y en el campo

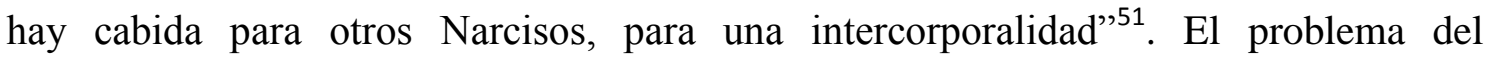
solipsismo, el problema de la multiplicidad de Narcisos, deja de ser un problema puesto que, a partir de la constitución de la carne como elemento articulador de una ontología originaria, la intercorporalidad precede a la corporalidad. Somos todos envueltos por este elemento común que antecede la constitución de todo principio de individuación.

Merleau-Ponty advierte, sin embargo, que, para la metafísica clásica era imposible pensar esto, e, incluso, sostiene que “(...) no existe nombre para designar esto en la filosofía tradicional"52. El ser no es algo "más allá" de los entes, ni, mucho menos, algo más allá del mundo. Por el contrario, el mundo es definido, por Merleau-Ponty, como "carne universal" 53 . El ser que tiene como correlato a la carne como elemento es un substrato que envuelve lo existente y no que se encuentra en la cima de una pirámide metafísica como la Idea de Bien platónica. "Mundo", "Carne", "Naturaleza", "Ser" se articulan como correlatos de una misma ontología con la cual Merleau-Ponty intenta sobrepasar los límites de la filosofía tradicional en general y del pensamiento especulativo en particular.

En este punto, es importante destacar la manera en que Merleau-Ponty comprende la relación entre ser y no ser. Para Merleau-Ponty, no se trata de términos absolutos que se vinculan solamente a partir de una relación de negación también. La carne no es una pura positividad, sino que está surcada por negatividades internas, por ausencias, por grietas.

Cuando hablamos de la carne de lo visible no pretendemos hacer una antropología, describir un mundo tapizado con nuestras proyecciones, con la salvedad de lo que pueda ocurrir detrás de

\footnotetext{
${ }^{51}$ Merleau-Ponty, M., Le visible et l'invisible, p. 183.

${ }^{52}$ Ibíd., p. 185.

${ }^{53}$ Ibíd.
} 
la máscara humana. Queremos decir, por el contrario, que el ser carnal, ser de varias hojas o varias caras, ser de latencia y presentación de ciertas ausencia, es un prototipo del ser, del que nuestro cuerpo, el sintiente sensible, es una variante muy notable pero cuya paradoja constitutiva se haya en todo ser visible: ya que en el cubo se juntan visibilia incomponibles, así como mi cuerpo es justamente cuerpo fenoménico y cuerpo objetivo: si, el cubo es, como mi cuerpo, por un prodigio extraordinario ${ }^{54}$.

En su texto Naturaleza y humanidad. El problema antropológico en la obra de Merleau-Ponty, Etiene Bimbenet afirma que, Merleau-Ponty solo logra su objetivo de sobrepasar la centralidad de la conciencia hacía una instancia ontológica más originaria en sus últimos textos ${ }^{55}$. Más allá de que si en obras tales como la Fenomenología de la percepción, lo haya logrado o no, a lo largo de este trabajo se ha demostrado que está búsqueda efectivamente atraviesa la obra de Merleau-Ponty. Ahora bien, las palabras recién citadas ponen de manifiesto la forma en que, en Lo visible y lo invisible, se presenta este proyecto. Esta ontología del ser carnal presenta una noción de ser en la cual lo negativo y lo positivo se entrelazan en una dialéctica de reciprocidades. En su instancia arqueológica-regresiva, Merleau-Ponty llega a esa dimensión previa en donde las tensiones y las concordancias, las ausencias y las presencias, se imbrican recíprocamente. Si, en la ontología fenomenológica sartreana, el ser y la nada se relacionaban por medio de la negación, en la ontología merleau-pontyana, se trata de una relación de reversibilidad, en donde ambos términos no son absolutos, sino relativos.

La ontología de la carne, que presenta Merleau-Ponty en Lo visible y lo invisible, no debe ser comprendida como una metafísica monista. El ser carnal que se identifica con

\footnotetext{
${ }^{54}$ Ibíd.

${ }^{55} \mathrm{Cfr}$., Bimbenet, E., Nature et humanité. Le probléme anthropologique dans l'oubre de Merleau-Ponty, p. 28.
} 
el ser natural o ser salvaje posee ya una dinámica de negatividades, positividades, un movimiento en donde hay alternancias, en donde lo latente y lo presente, se entrecruzan permanentemente. Por esto mismo, si, el monismo hace referencia a un principio que es en-sí, positivo, pura presencia, la ontología merleau-pontyana no presenta rasgos en común con él.

Mi carne y la del mundo, incluyen, pues, zonas claras, zonas de luz alrededor de las cuales giran sus zonas opacas, y la visibilidad primaria, la de los quale y de las cosas, no deja de tener una visibilidad secundaria, la de las líneas de fuerza y las dimensiones, la carne maciza va acompañada de una carne sutil, el cuerpo momentáneo de un cuerpo glorioso ${ }^{56}$.

En este punto, puede verse la forma en que la ontología merleau-pontyana es una ontología de la ambigüedad en donde las distinciones "claras y distintas" se diluyen en un pensamiento que, como señala el propio Sartre, se caracteriza por su circularidad. Hay un movimiento permanente, pero no al estilo engelsiano en donde de lo inferior se va a lo superior de manera casi teleológica, sino que, por el contrario, es un movimiento de alternancias, de giros, de "idas y vueltas", las "zonas de luz" conviven con las "zonas oscuras", para luego convertirse en ellas, y viceversa.

Para concluir este apartado, hay una cita que muestra, por un lado, el planteo de Merleau-Ponty, por otro, contrariando quizás a Cabestan, la forma en que el mismo Merleau-Ponty ve en su trabajo una continuación y reapropiación de la filosofía husserliana.

Cuando Husserl habla del horizonte de las cosas - de su horizonte exterior, que todos conocemos, y de su horizonte interior, esa oscuridad atiborrada de visibilidad, de la que la

\footnotetext{
${ }^{56}$ Merleau-Ponty, M., Le visible et l'invisible, p. 195.
} 
superficie de las cosas no es más que el límite - hay que tomar la expresión al pie de la letra; el horizonte como la tierra y el cielo, no es una colección de cosas tenues, o el título de una clase, i una posibilidad lógica de concepción, o un sistema de potencialidad de conciencia: es un nuevo tipo de ser: ser poroso, preñado, el ser de la generalidad, y en él está sumido el otro ser, aquel ante el cual se abre el horizonte. Su ser y las lejanías participan de una misma corporalidad o visibilidad en general, que reina entre estas y aquel, y hasta más allá del horizonte, más acá de la piel, hasta el fondo del $\operatorname{ser}^{57}$.

\section{V.- Conclusión}

En las páginas precedentes se ha visto la forma en que el intento por pensar una “tercera dimensión” entre el sujeto y el objeto atraviesa la obra de Merleau-Ponty. Si bien, en el despliegue del pensamiento merleau-pontyano, ha habido giros y cambios de perspectivas, dicho intento se ha mantenido siempre presente. Esto lo deja bien presente, el propio Merleau-Ponty, en "Títulos y trabajos", donde habla de las obras anteriores a este escrito al mismo tiempo que proyecta, desde una misma visión, sus futuras investigaciones.

A su vez, esa búsqueda de una dimensión originaria que preceda a todo dualismo tiene un carácter transversal que surca la gnoseología, la comprensión de la historia y la ontología. En el caso del debate con Sartre, esta búsqueda merleau-pontyana es una de las diferencias centrales con respecto al pensamiento del autor de El ser y la nada. Tanto en la Fenomenología de la percepción, como en Las aventuras de la dialéctica, como en Lo visible y lo invisible, Merleau-Ponty critica explícitamente varios aspectos del pensamiento sartreano, y la perspectiva, desde la cual realiza estas críticas, es la de

\footnotetext{
${ }^{57}$ Ibíd.
} 
este intento por buscar el suelo común, originario, entre los polos que, a primera vista, pueden ser antinómicos.

Las críticas a las “actitudes extremas", por su parte, también son llevadas a cabo, por Merleau-Ponty, desde esta perspectiva. "Intelectualismo" y "realismo", "subjetivismo" y objetivismo", "racionalismo" y "empirismo" son facetas de una misma lógica en la cual, o bien, se piensa al hombre como pura interioridad, o bien se piensa al hombre desde la pura exterioridad. Frente a dichas actitudes, Merleau-Ponty realiza, al mismo tiempo, una crítica y un reconocimiento parcial de cada una de ellas. Precisamente, esa convivencia entre crítica y reconocimiento, le abre la posibilidad de pensar una dimensión que preceda a las antinomias irreconciliables.

A partir de la lectura, análisis y exposición de los últimos escritos de Merleau-Ponty, se ha podido señalar la forma en que el filósofo francés busca rehabilitar una ontología de lo sensible en donde se relativice la agonística oposición entre el ser y la nada. En paralelo con lo dicho en el párrafo anterior, Merleau-Ponty intenta pensar una ontología que no incurra ni en el "positivismo" ni en el "negativismo". En este aspecto, se ha destacado el objetivo merleau-pontyano de pensar una ontología que no circunscriba el ser a la lógica de la metafísica tradicional ni a la de la pura positividad sartreana. El objetivo de Merleau-Ponty es plantear una ontología radical que piense al ser de manera también radical. En este sentido, la ontología de lo sensible se abre hacia una comprensión de la naturaleza en la cual esta se presenta como el "principio bárbaro" de Schelling, como aquello que se encuentra siempre presente, pero que, al mismo tiempo, no se reduce a un principio estático y absolutamente positivo, sino que se encuentra surcado por latencias y negatividades, por movimientos propios de autoproducción y de autotransformación. 
Así también, con la comprensión de la "carne" como elemento originario, MerleauPonty encuentra la posibilidad de pensar una noción de ser primordial que no se encuentre en la cima de una pirámide metafísica como la Idea de Bien platónica, sino, por el contrario, "recubra" la totalidad de lo existente. La carne se emparenta con la naturaleza como el ser salvaje, donde todos nuestros preliminares fueron hechos" y que articula todo lo existente. 


\section{Bibliografía:}

- $\quad$ Bimbenet, Étienne, Nature et humanité. Le probléme anthropologique dans l'oubre de Merleau-Ponty, Vrin, Paris, 2004

- $\quad$ Cabestan, Philippe, "La critique de l'ontologie sartrene dans Le visible et l'invisible”, Chiasmi Internacional N. 2. Merleau-Ponty de la nature à l'ontologie, VRIN, Paris, 2000. pp. 389-413.

- Carbone, Mauro, "Las ideas sensibles entre vida y filosofía", Merleau-Ponty viviente, Barcelona, Anthropos, 2012, pp. 100-102.

- Merleau-Ponty, Maurice, Collège de France. Résumés de cours 1952-1960, Paris, Gallimard, 1968.

, La Nature. Notes. Cours Collége du France, Paris, Gallimard, 1995. , Le visible et l'invisible, Paris, Gallimard, 1964. , Les aventures de la dialectique, Gallimard, Paris, 1955.

, Notes des cours au Collège de France. 1958-1959 et1960-1961, Gallimard, Paris, 1996.

, Parcours deux 1951-1961, Lagrasse, Verdier, 2000. , Phénoménologie de la perception, Paris, Gallimard, 1945. , Sens et non-sens, Paris, Nagel, 1963. , Signes, Paris, Gallimard, 1960. 
Éloge de la philosophie et autres essais, Paris,

Gallimard, 1953.

- Sartre, Jean Paul, L'être et le néant. Essai d’ontologie phénoménologique, Paris, Gallimard, 1943.

- $\quad$ Toadvine, Ted, "Nature and negation: Merleau-Ponty's Reading of Bergson", Chiasmi International 2. Merleau-Ponty. De la Nature à l'ontologie, Paris, Vrin, 2000. 